\title{
Positron emission tomography scanning and gastroenterology
}

\author{
Jean-Luc Urbain MD¹, Paul C Adams MD FRCPC², Editor-in-Chief
}

$\mathrm{D}^{\mathrm{s}}$ Jean-Luc Urbain is the Citywide Chief of Nuclear Medicine in London and the Chair of Nuclear Medicine at the University of Western Ontario, London, Ontario. He was actively engaged in Nuclear Medicine and Molecular Biology Research at Temple University in Philadelphia, Pennsylvania, USA where he received his $\mathrm{PhD}$ in Genetics and Molecular Biology. Dr Urbain has been a full Professor of Diagnostic Imaging for more than a decade and has held leadership positions in Nuclear Medicine and Molecular Imaging at Fox Chase Cancer Center (Philadelphia, Pennsylvania), the Cleveland Clinic (Cleveland, Ohio) and does so now at the University of Western Ontario.

Dr Urbain has been involved with positron emission tomography (PET) imaging since its early days in Belgium in 1984. He has given multiple lectures and seminars on PET and regularly teaches the diagnostic imaging community how to interpret PET images.

PA: Many gastroenterologists commonly deal with patients with gastrointestinal (GI) tumours. These tumours may be diagnosed by endoscopy, ultrasound and computed tomogra-

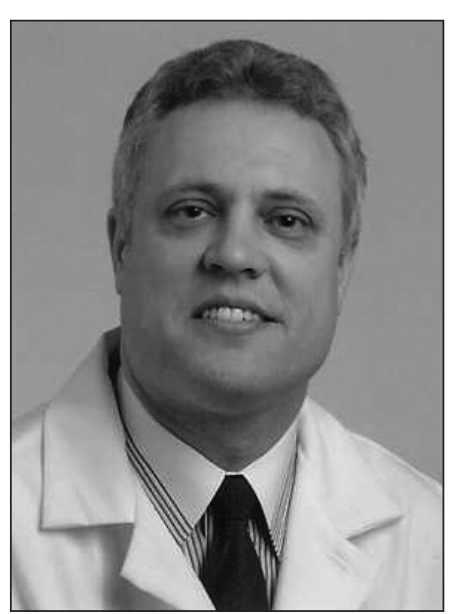

Dr Jean-Luc Urbain is the Citywide Chief of Nuclear Medicine in London, Ontario and the Chair of Nuclear Medicine at the University of Western Ontario (London) absorbed by tumours? Is this highly specific or are there falsepositive scans?

JLU: Deoxyglucose labelled in the $2^{\prime}$ carbon position by an atom of fluorine is absorbed by most cells as an analogue of glucose. To satisfy their increased metabolic needs, cancer cells preferentially take on 18 -fluorine-labelled $\left({ }^{18} \mathrm{~F}\right)$ FDG by overexpressing the glucose transporters at their surface and switching their metabolic pathways in high gear toward the production of ATP. ${ }^{18}$ F-FDG enters the early steps of the glycolytic pathway and rapidly becomes trapped inside cancer cells, reflecting their higher uptake and metabolism. The sensitivity and specificity of ${ }^{18}$ F-FDG PET scanning to detect tumours varies in function of the type of tumour, its metabolism, aggressiveness and size. PET scintigraphy has a sensitivity and specificity of approximately $90 \%$ for detecting the recurrence of colorectal carcinomas.

Inflammatory and infectious processes can generate false-positive scans because inflammatory cells also avidly absorb ${ }^{18}$ F-FDG. Remember that glucose is not a specific substrate.

PA: Can you comment on hybrid scans of the abdomen in the assessment of GI tumours?

JLU: Hybrid imagers, such as combined PET/CT scanners, give you the best of both worlds in 'one-stop shopping' by providing information on the metabolic stage of the tumour, and its precise size and localization in the body. The superiority of these hybrid PET/CT scanners over PET-only machines became evident very quickly after their introduction in 2000. Today, no major manufacturer of medical imaging still produces PET-only scanners.

PA: It is implied that an early diagnosis of advanced cancer may lead to more appropriate therapies or the avoidance of surgery when it will not be curative. Have these concepts been fulfilled in clinical practice?

JLU: As a rule of thumb, prevention in medicine is always better than therapy. The ability of PET imaging to detect metabolically overactive tumours with a size of approximately $0.5 \mathrm{~cm}$, very early on, enables a curative surgical approach before the cancer has metastasized. Unnecessary surgeries can also be avoided if the PET images demonstrate a significant spread of the disease. We have seen many cases of patients with colorectal carcinoma who were referred for restaging due to elevated carcinoembryonic antigen levels who had unsuspected metastases in the lung and/or liver. Some private centres in the United tumours with FDG and radiolabelled amino acids. Overall, PET scintigraphy with FDG significantly changes the management of patients with GI tumours by understaging and overstaging approximately $30 \%$ of cases.

In combination with CT in hybrid PET/CT equipment, PET scintigraphy seems to promise an even greater impact.

PA: Can you remind us of why the isotope is preferentially

${ }^{1}$ Department of Nuclear Medicine, Univeristy of Western Ontario; ${ }^{2}$ University Hospital, London, Ontario

Correspondance and reprints: Dr Jean-Luc Urbain, Nuclear Medicine Department, St Joseph's Health Care, 268 Grosvenor Street, London,

Ontario N6A 4V2. Telephone 519-646-6000 ext 64954, fax 519-663-3549, e-mail JeanLuc.Urbain@sjhc.london.on.ca

Received and accepted for publication July 31, 2007 


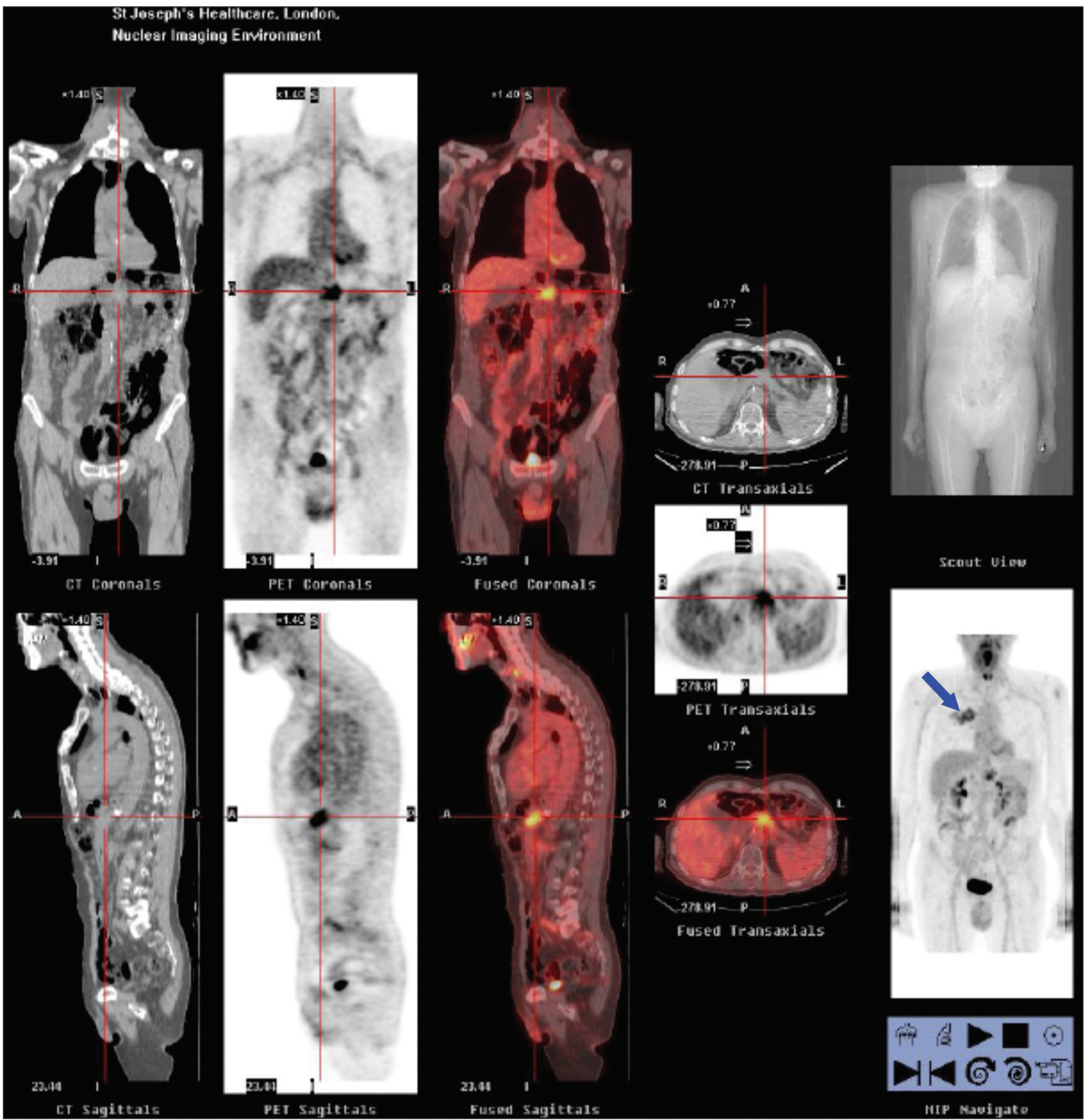

Figure 1) Combined positron emission tomography (PET)/computed tomography (CT) scanning images of a 65-year-old patient with pancreatic carcinoma (red cross-hair lines) on the coronal, sagittal and transaxial CT, PET and fused images and lung metastasis to the right upper lung (blue arrow)

States have begun to offer preventive whole-body PET/CT scanning in a model that is similar to the detection of breast cancer with mammography.

PA: It seems as though some provincial governments have not endorsed the use of PET scanning. Can you provide us with a synopsis of both sides of this argument, as well as what we may expect in terms of availability in Canada in the future?

JLU: Most countries have long recognized the usefulness of PET scanning with ${ }^{18} \mathrm{~F}$-FDG in the staging, restaging and therapeutic follow-up of patients with various types of tumours. PET imaging with ${ }^{18} \mathrm{~F}$-FDG is now covered by the provincial health care authorities in Quebec and British Columbia. For some arbitrary reasons that I suspect to be essentially financial in nature, Ontario has chosen the path of redemonstrating to the rest of the world that ${ }^{18} \mathrm{~F}$-FDG PET is useful in patients with cancers by performing limited scope trials. The diagnostic imaging and oncology communities are hoping that by 2010, most Canadian provinces will develop some common sense and provide wide coverage for PET imaging with ${ }^{18} \mathrm{~F}$-FDG, which has repeatedly been shown around the world to dramatically improve the management of patients with cancer. 


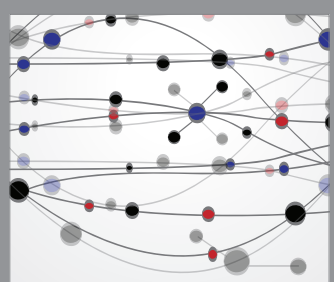

The Scientific World Journal
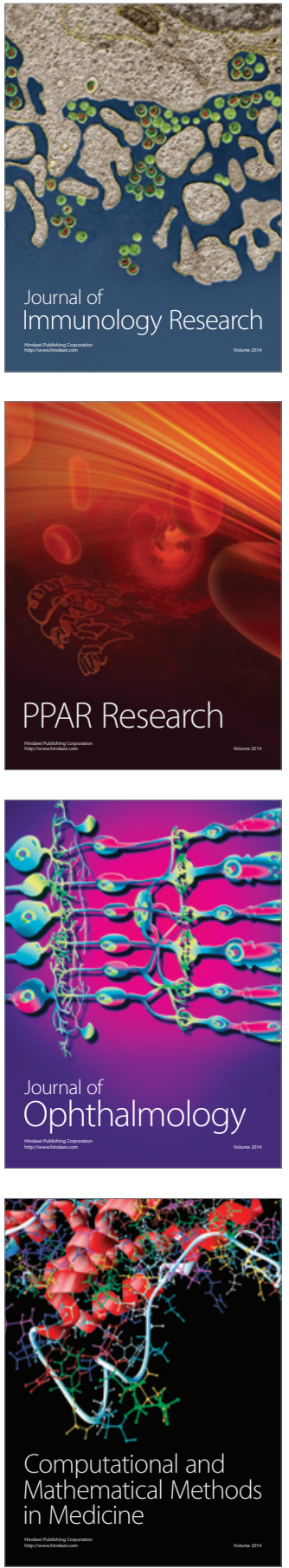

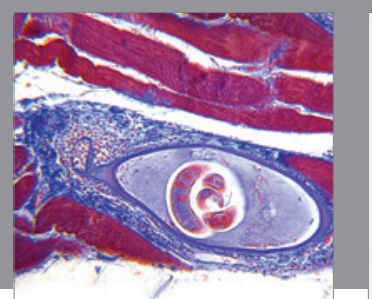

Gastroenterology Research and Practice

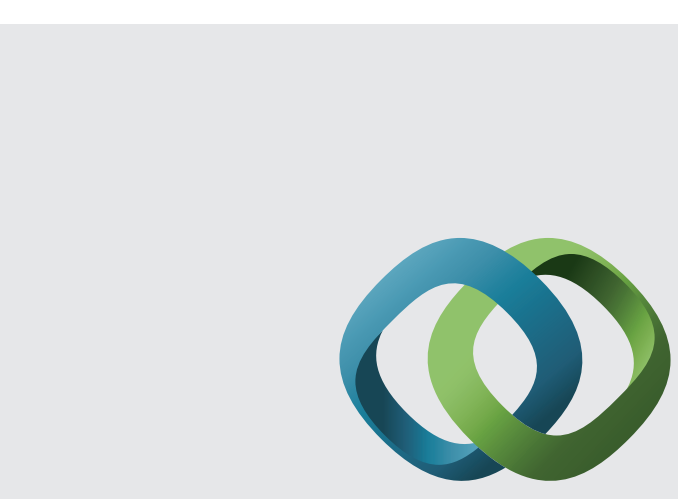

\section{Hindawi}

Submit your manuscripts at

http://www.hindawi.com
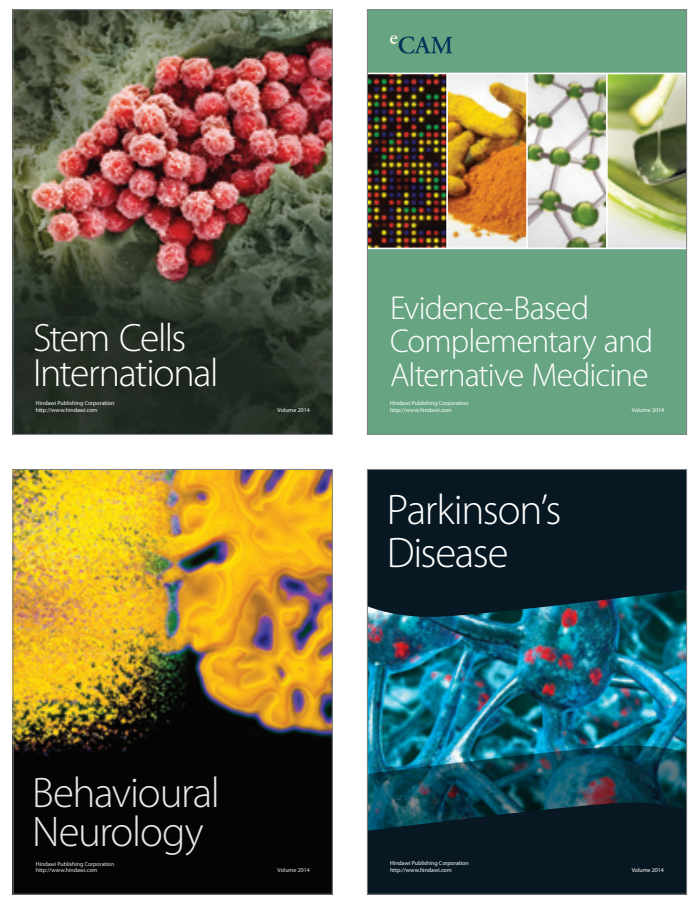
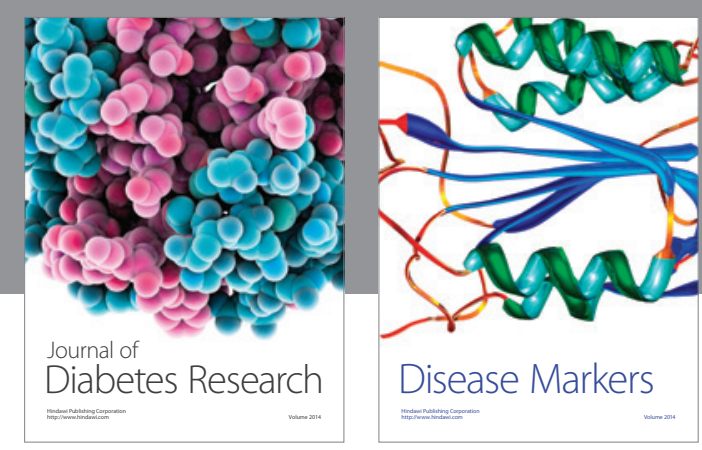

Disease Markers
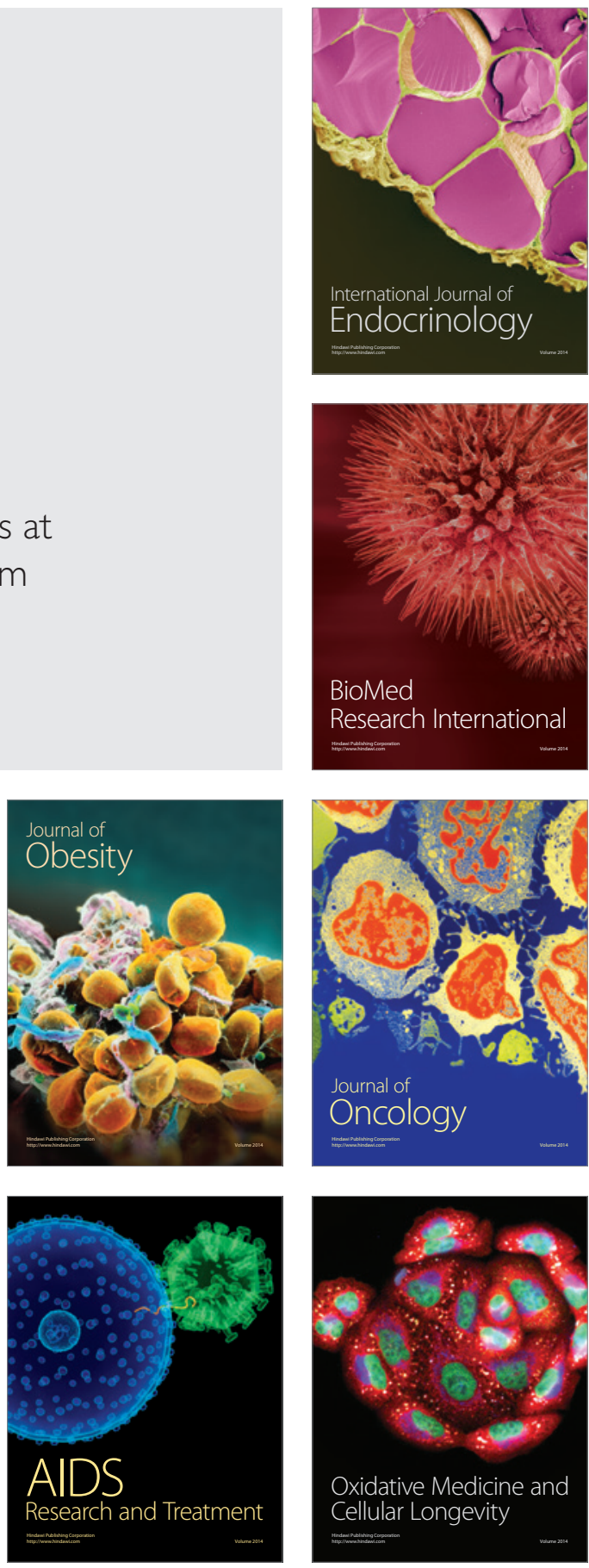